\title{
Crônicas de uma biblioteca escolar
}

\author{
Roseli Venancio Pedroso \\ Bibliotecária do Colégio Dante Alighieri (SP) \\ E-mail: roseli.venancio@uol.com.br \\ http://bibliotequiceseafins.blogspot.com \\ http://sonhosmelodias.blogspot.com \\ http://coletivoclaraboia.wordpress.com/
}

\section{Introdução}

Trabalhando em biblioteca escolar desde 1991, presenciei muitas situações ocorridas dentro de uma biblioteca. O universo juvenil é rico e aprendo muito com esses pequenos seres em formação. Ao lado deles, cresci, passei a ser mais tolerante, ter mais humor. Percebi que devemos ser mais flexíveis diante das situações e, acima de tudo, acredito que hoje, após todos esses anos, tornei-me mais humana. Ah! E com um detalhe: alcancei um trunfo que poucos têm: absorvo a juventude que eles emanam próximos a mim. Com isso, apesar de minha idade já avançar, mantenho-me com o espírito jovial de quando tinha 15 anos com a experiência que trago hoje.

Foram tantas experiências vividas nesse espaço do conhecimento, que cheguei à conclusão que precisava registrar no papel ou, como decidi por hora, no virtual.

E hoje, dou o pontapé inicial das muitas aventuras extraclasse que presenciei ou que fiquei sabendo que aconteceu. São histórias engraçadas, algumas bizarras, outras tristes, mas, uma coisa todas tem em comum: são histórias onde o papel principal são os adolescentes contracenando com a biblioteca escolar. O que antes poderia parecer algo inusitado, hoje pelo menos para mim - está muito claro. Há um universo muito rico e diversificado entre as quatro paredes que comportam inúmeros livros, estantes, computadores e placas de "Silêncio". Existe uma vida pulsante e ininterrupta que vibra, ri, chora, esbraveja e muitas vezes, com lágrimas aos olhos nos buscam para dizer um "Muito obrigado" por nossa orientação e ajuda numa pesquisa escolar.

Hoje para mim, uma biblioteca escolar é muito mais que um recinto cheirando a mofo de livros velhos, estantes empoeiradas e um silêncio sepulcral. A biblioteca passou a ser uma fábrica contínua e prolífica de vidas acontecendo. E para minha total alegria, faço parte fundamental delas. A partir de agora, faço o convite para que vocês me acompanhem nessas histórias e muitas aventuras ocorridas entre estantes e livros. 
Mergulhe comigo. Devo avisar que o risco que se corre é grande e que fatalmente após as primeiras histórias lidas, você se observe com todos os sintomas de uma condição virótica. Não será apenas impressão. Você com certeza estará contagiado pelo vírus de uma doença muito séria e crônica: amor incondicional aos livros, à leitura e à biblioteca. Mas tenha calma, isso não é fatal. Poderá levar uma vida praticamente calma e tranqüila desde que, pelo menos uma vez por semana, compareça a uma biblioteca. Ah! Já ia me esquecendo: não se esqueça também de ter sempre em mãos um bom livro. A leitura acalma, dá paz de espírito e te proporciona uma boa noite de sono.

Vamos começar?

\section{Como descobri esse templo}

Após uma corrida louca para encontrar um emprego que me possibilitasse manter minha faculdade de arquitetura, recebi o convite para trabalhar numa biblioteca escolar de um colégio próximo de onde morava. Na época, não fazia idéia do que se fazia em uma biblioteca. Muito menos numa biblioteca escolar. Pensei bastante e decidi marcar uma entrevista com a bibliotecária responsável por ela.

Ao chegar, achei-a pequena, acanhada e muito desorganizada. A bibliotecária me falou sobre a rotina dali e achei que não teria problemas em aprender o serviço. Como estava mesmo precisando de dinheiro para me manter, aceitei.

Resolvida todas as questões trabalhistas entre entregar os documentos necessários, fazer os exames solicitados e a total aprovação da diretoria do colégio, finalmente chegou o meu primeiro dia de trabalho nela.

As 7 h30 da manhã adentrei os portões da escola, segui até a recepção e me anunciei. Imediatamente a moça me passou as chaves da biblioteca e me entregando os jornais do dia falou que já podia subir.

O meu primeiro contato com os jovens foi atravessando o pátio em direção ao prédio onde ficava a biblioteca. Foram tantos olhares curiosos me medindo e fazendo uma avaliação sobre a nova auxiliar de biblioteca. Isso, ao mesmo tempo em que me trouxe uma insegurança, trouxe um calor diferente que nunca havia sentido. 
Já dentro do recinto, guardei minha bolsa e comecei as aventuras pelos corredores de livros empilhados, muitas caixas pelos cantos, duas mesas abarrotadas de papéis e mais livros. Pensei comigo: E agora? O que faço? Liguei para a secretaria e perguntei a que horas a bibliotecária chegaria. Qual não foi minha surpresa ao saber que ficaria a manhã inteira sozinha e que, em dez minutos, o sinal do recreio soaria e muitos alunos viriam à biblioteca. O pânico tomou conta de mim. O que faria quando inúmeros alunos invadissem a biblioteca em busca de livros, pedindo pesquisas e eu não sabia de nada! Tomada por esses pensamentos, me vi de repente com vários pares de olhos aguardando resposta a algumas perguntas que já haviam feito e eu nem tinha ouvido por conta de meu nervosismo.

- Tia, por favor! Empresta-me o livro de matemática!

- Tia, rápido! Me vê o livro de biologia! Rápido, ainda não lanchei!

- Tia, por favor! O livro de geografia!

Tia, tia, tia! Meu Deus! O que faço! Não sei que livros são esses, nem onde ficam!

Após alguns segundos que valeram por uma eternidade, falei a todos que era nova e que não sabia que livros eram esses, nem onde ficavam. Então, um garoto falou:

- Ah! Sem problemas! A gente sabe onde ficam. Olha, o meu de matemática fica naquela estante azul e o livro é verde com uma calculadora na capa.

- Imediatamente segui sua indicação e procurei o tal livro. Para minha felicidade, acheio e entreguei ao garoto que me falou:

- Moça, você precisa fazer o empréstimo de uma semana pra mim. Olha, tá vendo essa caixa de acrílico cinza? Aí na mesa? Então, minha ficha fica aí, a senhora pega, anota o número do livro e a data de devolução. É fácil!

- Ah! Meu nome é Francisco Gomes da Silva. A fichinha tá pelo sobrenome.

Corri para a tal caixinha e procurei sofregamente a tal ficha. Achei, anotei, e entreguei o livro ao garoto agradecendo. E assim, sucedeu os demais empréstimos da manhã. Todos me ajudando a localizar o livro e, em tempo recorde, aprendi a primeira grande lição de minha profissão: fazer um empréstimo de livro.

Quando às 14h00, chegou a bibliotecária, ela me olhou curiosa e perguntou:

- Oi! Tudo bem? Como foi sua manhã? Algum problema? 
- Boa tarde! Está tudo muito bem! Minha manhã foi magnífica e aprendi muitas coisas hoje.

- É mesmo? O quê?

- Solidariedade!

- Ah!...Certo. A propósito, desculpe-me não estar aqui hoje cedo para te orientar em seus afazeres. Tive outro compromisso. Venha, vou te mostrar como se faz empréstimo de livros e te mostrar as estantes e onde se encontram as classificações dos livros.

- Não precisa não! Já vi tudo pela manhã e aprendi a fazer empréstimo. Fiz vários. Pode conferir. Estão todos aqui.

Num misto de espanto e curiosidade, a bibliotecária verificou meu serviço e certificouse que estava tudo correto. Elogiou-me dizendo que era esperta inteligente e que aprendia fácil e rápido as coisas.

Sorrindo, pensei com meus botões que aqueles garotos e garotas foram de uma atitude solidária comigo que não havia visto em nenhum lugar que tinha trabalhado. Esse meu primeiro contato com eles foi, hoje tenho certeza, fundamental pela futura escolha de minha profissão. Pela primeira vez, me senti acolhida e aceita de imediato pelas pessoas.

Pela primeira vez, num ambiente profissional, me senti em casa!

\section{Transformação de um Menino num Homem}

Já trabalhava nessa biblioteca uns quatro meses quando tive o desprazer de conhecer um garoto no mínimo insuportável. O típico garoto problema: extremamente mimado mal educado e sofria da síndrome de Príncipe Herdeiro. Sabem o que isso significa? Explico: pessoa que teve em sua formação (ou devo dizer De-formação?) a mania de se achar acima de tudo e de todos. Acredita seriamente que o mundo existe para lhe servir.

O rapaz fazia e acontecia naquela escola. Ninguém o suportava, mas devido a sua origem, seu sobrenome, todos tratavam de tolerá-lo. Ele se achava o máximo! Atormentava as garotas da classe, ofendia as professoras com palavrões indescritíveis, peitava os bedéis do 
colégio e ainda debochava dos funcionários da limpeza fazendo questão de sujar onde eles acabavam de limpar. Simpática a criatura não?

Numa bela manhã, no primeiro intervalo para o recreio do ensino médio, a biblioteca lotada, eu sozinha no atendimento pra variar e eis que essa bela criatura adentra o recinto. De imediato o clima na biblioteca se alterou. O rapaz atormentava a todos até que tentou tirar o jornal do dia e recortar algo que ele tinha interesse.

- Garoto pode deixar o jornal onde está e, por favor, deixe a tesoura no lugar.

- Ah! Não pode usar a tesoura? Tá bom!

Fazia o empréstimo de um livro de física para uma aluna quando ouvi um som de papel se rasgando. Levantei meus olhos e não acreditei no que vi: o rapaz estava rasgando a notícia que lhe interessava. Tornei a falar com ele no que ele me respondeu:

- Você só falou que não podia usar a tesoura e não que era proibido usar minhas mãos para recortar o jornal.

- Rapaz tenho certeza que você não é tão obtuso quanto deseja aparentar. Por favor, entendeu perfeitamente o que disse. O jornal do dia é para ficar intacto para que todos possam ler. Se tiver algo que te interessa, me avise que separo e amanhã te passo sem maiores problemas. Entendeu?

Tornei a me ocupar atendendo outros alunos quando ouço ele falar:

- Se essa vaca pensa que vou desistir disso está muito enganada. Quem ela pensa que é?

Bom, não preciso nem dizer que o sangue subiu até o tampo de meu cocuruto e num átimo de segundo, havia dado a volta no balcão que nos separava e frente a frente com o simpático rapaz inquiri:

- Repete o que disse olhando agora nos meus olhos! Repete!

- O quê tia?! Tá maluca? Não falei com você!

- Cadê o valentão? Não é você que vive pelos cantos dizendo que faz e acontece? Prova sua valentia me olhando dentro dos olhos e repetindo aquilo que acabou de dizer pelas minhas costas. FALE!

- Não sei do que você está falando... eu heim?! 
Voltei para os outros alunos que ali no balcão já se encontravam e perguntei à eles:

- Vocês ouviram muito bem o que ele falou agora a pouco não ouviram?

- Sim, eu ouvi muito bem. Disse um garoto me olhando de forma solidária.

- Eu também ouvi tia. Outra garota falou olhando para mim e depois para o rapaz que me agredira verbalmente.

- Muito bem. É só do que preciso: testemunhas. Vocês me acompanham até a sala do diretor? Vocês podem testemunhar sobre o ocorrido? Tem algum problema?

- Não! Disseram os dois juntos.

- Ótimo! Pessoal, a biblioteca está fechando! Por favor, queiram sair, pois tenho que fechá-la. Você não garoto. Você fica e só sai comigo e esses dois direto para a sala do diretor.

- Qualé tia? Tá maluca? Eu não fiz nada!

- Você fica! Falei enfaticamente olhando-o nos olhos de forma bem grave.

Após fechar a biblioteca, chamei um rapaz da disciplina e pedi que nos acompanhasse até a sala do diretor.

Ao nos receber e ouvindo atentamente ao que eu disse, ao que os garotos confirmaram o diretor voltou sua atenção ao acusado e falou:

- Muito bem, muito bem, muito bem heim meu rapaz? De nada tem adiantado nossas inúmeras conversas e orientações! Você parece ter um prazer imenso em maltratar as pessoas que te rodeiam. Lembre-se da última conversa que tivemos? O que foi que disse à você? Lembra-se?

- Sim, diretor! O senhor falou que da próxima eu ia embora da escola. Mas, por favor! Não faça isso! Meus pais me matam!

- Por favor, senhor diretor!

Olhando para mim de forma suplicante, ele pediu:

- Por favor, moça! Eu vou ser expulso do colégio! 
- Meu jovem, eu não tenho intenção alguma de ajudar a expulsar ninguém. Mas vamos combinar: você é muito abusado! Quem você pensa que é? Humilha, ofende as pessoas e acha que está tudo bem? Qual o problema com você? O que falta em sua vida menino?

- Você não quer ser expulso do colégio? Então se arrependa sinceramente e peça desculpas à bibliotecária por sua atitude infeliz. Vamos, estou esperando!

- Tudo bem diretor, mas...tem de ser na frente desses dois?

- Pode apostar que sim meu jovem! Isso se não quiser que o colégio inteiro seja chamado para te ouvir. Vamos! Pode começar!

Por alguns segundos que pareceram uma eternidade, ele me olhava com os olhos marejados e com um nó na garganta que o impedia de falar. Só saía uns grunhidos indecifráveis. Após um tempo que se tornou desagradável a todos ali naquela sala, o diretor falou:

- Anda logo com isso que não tenho o dia inteiro. Vamos!

- De-Desc..ulpa...saiu quase imperceptível

- Não ouvi. Fala mais alto. Disse o diretor.

- Esculp...aaah Lágrimas já escorriam por sua face desfigurada

- Continuo não ouvindo direito. Mais alto sim? Falou o diretor de forma mais grave, olhando-o firmemente.

- Senhor diretor, eu já entendi que ele está arrependido. Não precisa repetir. Disse me sentindo muito mal por, de certa forma, ser a responsável por tal situação.

- Senhorita, eu ainda não entendi. Não tenho sua sensibilidade. Quero ouvir nitidamente as desculpas dele. Pode prosseguir.

- Desculpa moça! Desculpa, por favor, desculpa! Nunca mais falarei assim com você! Após esse desabafo, caiu num choro convulsivo que dava dó.

Todos naquela sala ficaram emocionados e, com os olhos cheios d'água, o diretor respirou fundo, fungou um pouco, pigarreou e disse: 
- Rapaz acredite que hoje sua pele foi salva pelo coração sensível dessa garota nova da biblioteca. Mas entenda de uma vez por todas. Aprenda a respeitar as pessoas ou irá sofrer muito ainda nessa vida. Vá e nunca mais repita isso com ninguém, pois da próxima, não haverá perdão. É expulsão na certa. Vá!

Após esse episódio, nunca mais esse rapaz me atormentou. Ao chegar ao último dia do ensino médio, ele foi até a biblioteca se despedir de mim e pediu para eu não guardar raiva dele pelo ocorrido no passado. Desculpou-se mais uma vez e foi-se embora.

Anos mais tarde, passando em frente ao SESC Consolação, quase tomei um esbarrão de um moço que saía apressado de lá. Imediatamente se desculpou de forma educada e preocupado quando nos olhamos e imediatamente nos reconhecemos.

- Tia da biblioteca!!! Tudo bem? Lembra de mim? Virei gente, entrei na faculdade! Estou estudando no Mackenzie, aqui ao lado.

- Oi menino! Nossa! Como você cresceu! Está um homem! É claro que me lembro de você. E então? Só cresceu no tamanho ou também amadureceu?

- Tia mudei! Virei homem de verdade! Acredite, não sou mais um mala como era quando moleque. Até namorando estou! Estou trabalhando e tudo! E muito do que sou hoje devo a você por ter me dado outra chance. Obrigado de novo! E

- Aí? Trabalha ainda no colégio?

- Não. Trabalho agora em outro colégio. Fico feliz em saber que está bem.

- Boa sorte e tudo de bom em sua vida.

Conversamos mais alguns minutos e depois se despedindo, cada um seguiu seu rumo. Sai feliz desse encontro casual sabendo que minha atitude no passado ajudou a firmar o caráter de um jovem que se encontrava perdido. Após o triste episódio, retornei a minha rotina na biblioteca e até ele se formar, tratei-o sempre com respeito e não o descriminei como tantos o faziam. Acredito que isso o tocou e ajudou a repensar sua atitude com os demais. Esse é um dos ganhos na profissão que escolhi. Vejo e de alguma forma colaboro na lapidação desses jovens que pouco a pouco vão se firmando, amadurecendo e aprendendo para a vida. Não é somente com sugestões de leitura e no auxílio em suas pesquisas escolares que me torno uma 
peça importante em suas vidas. De certa forma, sirvo de bússola em suas buscas pessoais. E isso é bom demais! Acompanhar um menino se transformar num homem!

\section{Acompanhar os flertes que surgem entre os jovens}

Uma biblioteca escolar não é somente um espaço para leitura e desenvolvimento de pesquisa e trabalhos escolares. Quem tem essa imagem está bem equivocado. Uma biblioteca escolar costuma ser um ponto de encontro da galera e, principalmente, um local para paqueras. Sim pessoas! Por entre estantes e livros, olhares se buscam e se encontram para a formação de futuros casais. E como é ao mesmo tempo engraçado e bonito de se ver os relacionamentos surgindo. Algumas vezes de forma bem tímida, outras mais ousadas mas sempre acontecendo.

Lembro bem uma situação que aconteceu logo que comecei a trabalhar em escolas.

$\mathrm{O}$ ano letivo iniciava e todos os alunos estavam em total alegria e costumavam conversar entre grupos de forma animada querendo saber quais as novidades do ano. $\mathrm{O}$ que tinham feito nas férias, o que havia "rolado" de bom, as paqueras de férias e, por último, quem eram os alunos novos daquele ano.

Como o colégio era relativamente pequeno, um aluno novo que entrasse já se tornava imediatamente conhecido, pois nada passava despercebido.

Fabrício. Sim, esse era seu nome. O garoto havia se matriculado para o primeiro ano do ensino médio e já era notícia em toda a escola. Todas as meninas queriam conhecê-lo, pois já corria a notícia que ele era lindo! Um verdadeiro príncipe!

Uma bela tarde estava eu guardando alguns livros nas estantes quando entrou uma garota. Tatiana, da $6^{\mathrm{a}}$ série do período da manhã. Cumprimentou-me, pegou uma revista e sentou-se de forma displicente e passou a folhear a revista sem nem ao menos olhar para ela. Observei que Tatiana não tirava os olhos da porta e parecia inquieta. Isso me atiçou a curiosidade e como conheço os alunos, pensei comigo:

Essa garota está aprontando. O que será que ela está esperando? Ou, melhor formulando a pergunta: Quem ela está esperando que apareça aqui na biblioteca?

- Humm...Oi Tati!!! Tudo bem com você? Precisa de alguma coisa? - inquiri a aluna. 
- Ah, oi tia! Ehhhhmm, tia você já conhece o aluno novo do primeiro ano?

- Não. Ele ainda não apareceu por aqui. Mas já ouvi falar bastante nele. Aliás, não se falam em outra coisa nesse colégio desde que as aulas começaram. Por quê?

- Ai tia, ele é lindo demaisss!!! Ai acho que me apaixonei!

- É mesmo Tati? E já conversou com ele?

- Não. Não tive coragem de me aproximar. Mas já tratei de fazer amizade com o irmão dele e já tenho a ficha completa.

- Sério mesmo? E como é o irmão dele? Tão bonito quanto ele? Ou mais?

- Não tia! É muito difícil ser tão bonito ou mais que o Fabrício. O Caio é legal, boa pinta, camarada, mas... Parou aí... Jesus! Tia olha ele entrando!! Humm...

Na mesma hora olhei para a entrada da biblioteca e vi um moço realmente bonito de se ver. Moreno, olhos verdes cristalinos, porte atlético e um sorriso encantador ao se voltar para mim e perguntar se era responsável pela biblioteca.

- Sim, sou a responsável. Por favor, deixe-me mostrar a biblioteca e como ela funciona.

- Obrigado. Meu nome é Fabrício e se tem uma coisa que gosto, essa coisa se chama biblioteca e livros. Adoro ler!

- É mesmo? Nossa! Fico muito contente em saber disso. Um motivo a mais para te mostrar tudo o que temos por aqui.

Enquanto mostrava a biblioteca ao mais novo usuário, Tatiana olhava o rapaz de forma petrificada. Parecia até que não respirava. A todo o momento, tentava chamar a atenção do moço, mas, em vão voltou para a mesa em que estava, pegou sua revista e de forma dissimulada, fingiu interesse em sua leitura.

Após fazer sua inscrição e carteirinha na biblioteca, Fabrício ficou por ali mais algum minuto, se despediu de mim e se foi.

Tati inconformada guardou a revista e, de cabeça baixa se despediu de mim e também se foi. 
Por dias, semanas, essa cena aconteceu sem haver nenhuma alteração. Era Tati tentando chamar a atenção de Fabrício e ele, ignorando ela por completo. Já começava a sentir pena da pobre menina apaixonada.

Uma bela tarde após as aulas, a garota chegou até mim e fez a seguinte pergunta:

- Tia, você que já é mulher feita e já tem experiência de vida me diga uma coisa: você acha que o Fabrício nem olha pra mim porque me acha uma criança ainda?

- Puxa menina. Não sei lhe dizer. Você é linda! Não sei talvez ele seja apenas tímido. Está chegando na escola agora, não conhece ninguém. Talvez esteja estranhando o ambiente e as pessoas. Dê mais um tempo pra ele. Ou melhor, já que fez amizade com o irmão dele, por que não pede para serem apresentados?

- Já pensei nisso, mas ai acho sacanagem com o Caio. Ele vai sacar que só fiz amizade com ele por causa do irmão dele. Chato isso né?

- É. Isso lá é verdade. Ah! Idéia! Eles nunca ficam juntos? De repente, você pode chegar neles, e aí, não vai ter jeito. Caio vai ter que te apresentar a ele. Daí, pra fazer amizade é um dois.

- Já pensei nisso também. Mas toda vez que o vejo, me dá uma tremedeira! Que saio correndo tia! Ai sou uma boboca mesmo né? E fora que está assim de meninas mais velhas e mais bonitas que eu rondando ele o tempo todo!

O tempo foi passando rápido e quando dei por mim, já era época das provas e uma bela manhã chegou uma das orientadoras do ensino médio e pediu um favor muito especial para mim:

- Oi Rosinha!!! Tudo bem? Escuta, preciso de um favor enorme de você e preciso também de sua total descrição quanto ao assunto. Seguinte: sabe o aluno novo do primeiro ano do ensino médio? O galã das menininhas, Fabrício?

- Sim, sei quem é professora. O que tem ele?

- Pois bem. Acredita que na primeira prova bimestral ele foi super mal em todas as provas e isso chamou a atenção de todos afinal, suas notas na outra escola eram altas e de repente, não fez praticamente nada aqui. A questão foi muito discutida entre os professores e decidi ligar para sua mãe. Ao saber disso ela marcou comigo uma 
reunião pessoal e hoje, ela conversou bastante comigo e explicou que a culpa foi dela por ter se esquecido de um detalhe tão importante como esse. Ela me confidenciou que Fabrício sofre de uma doença nos olhos que está pouco a pouco o cegando e ele, morre de vergonha de usar óculos tão grossos e, como não pode usar lentes de contato, prefere enxergar pouco e faz sempre silêncio com relação a esse assunto. Por isso, ao receber suas provas para resolver, com a fonte das letras normais, ele não conseguia enxergar absolutamente nada a não ser um grande borrão. Conclusão: não conseguindo ler, não fez nada ou quase nada. Então sua mãe pediu para fazermos as provas dele na maior fonte possível para que ele possa ter condições de ler e resolver.

- Uau!! Professora que babado não? E as meninas achando que ele é esnobe, pois não olha para nenhuma delas. O coitado apenas não enxerga! Isso que dizer que ele vai ficar cego de vez?

- É Rosinha. Quase isso. A doença tem que praticamente cegá-lo para só então ele passar por uma cirurgia e fazer o transplante de córnea. Agora, voltando ao assunto das provas, por favor, faça num horário em que não tenha ninguém por perto e, por favor, conto com seu sigilo tanto com relação à prova, como também em relação a esse assunto da doença que tanto o incomoda. Posso contar com você?

- Sem dúvida professora. De minha boca ninguém vai saber nada.

E assim foi. Fiz as cópias de todas as provas e Fabrício pôde fazer suas provas de forma confortável recuperando assim suas notas altas pois o garoto era muito inteligente e um excelente estudante.

Voltando à menina Tatiana, infelizmente suas inúmeras tentativas de se fazer notar por Fabrício foram infrutíferas. Ela até conseguiu fazer amizade com ele, mas parou por ai. Fabrício realmente não conseguia enxergar nela o belo botão em flor que prometia ser. Garota desabrochando pouco a pouco sua feminilidade, mas que ainda não se fazia perceber por ele. Passados dois anos, uma bela manhã quando estávamos a sós na biblioteca voltamos a falar nele e Tatiana num desabafo falou:

- Tia Rose, depois de muito pensar e de muito chorar, decidi esquecer o Fabrício. Não adianta mesmo. Ele jamais vai me olhar de forma diferente. Para ele serei sempre a "menina engraçadinha" amiguinha de seu irmão. Nada mais. É uma pena pois gostei demais dele mas quer saber? Tia conheci um garoto numa festa que fui nesse final de 
semana que é uma graça!!! E ele está muito a fim de sair comigo e até pegou meu telefone. Vou partir pra outra. Chega de chorar por alguém que nem repara que você existe!

- Tati fico feliz em saber que você já esta partindo para outra. Entendo seu sofrimento, pois na sua idade, também chorei muito por alguns rapazes. É normal, faz parte de nosso conhecimento e crescimento. Em breve ele será apenas uma doce lembrança de sua pré-adolescência.

Conversamos mais um pouco, ela me falou sobre seus planos e após ela ir embora, guardando alguns livros na estante sorri por dentro e ao mesmo tempo em que achava graça na situação fiquei penalizada com a realidade de Fabrício. Um jovem tão privilegiado em sua beleza física que arrancava suspiros pelos corredores do colégio, mas que era incapaz de usufruir dessa sua fama de "Gato" por não conseguir enxergar um palmo a sua frente. E esse enxergar era ao pé da letra mesmo. Por conta da doença em sua visão ele perdia muitas coisas belas que o rodeavam. Quando estava prestes a sair do colégio rumo a um novo emprego fiquei sabendo que sua cirurgia havia sido marcada e que havia grande chance de ser bem sucedida. Torci muito por ele, pois nutria um carinho muito especial por esse jovem. Nunca mais tive notícias nem dele, muito menos da Tatiana, mas sempre me recordo deles com muito carinho e saudades daqueles tempos. 